\section{Emergency department use during COVID-19 as described by syndromic surveillance}

\author{
Helen E Hughes (10,1,2 Thomas C Hughes (1) , ${ }^{3}$ Roger Morbey (1) , \\ Kirsty Challen 이, ${ }^{4}$ Isabel Oliver (1) , ${ }^{5}$ Gillian E Smith (ㄷ) , \\ Alex J Elliot (1) ${ }^{1}$
}

COVID-19, while acute respiratory infection was reduced by $-4.4 \%(95 \% \mathrm{Cl}-9.5 \%$ to $0.6 \%$ ). ED attendances in England have been particularly affected during the COVID-19 pandemic due to changes in healthcare seeking behaviour. EDSSS has enabled realtime daily monitoring of these changes, which are made publicly available to facilitate action. The EDSSS provides valuable surveillance of ED attendances in England. The flexibility of EDSSS allowed rapid development of new indicators (including COVID-19-like) and reporting methods.

\section{BACKGROUND}

The COVID-19 pandemic has had major health and societal impacts worldwide. In the UK, the 'delay phase' was introduced in stages from 12 March 2020, including social distancing and shielding measures. ${ }^{1}$ These have had a major impact on population movement, day-to-day activities and healthcare seeking behaviours.

The Public Health England (PHE) Emergency Department Syndromic Surveillance System (EDSSS) is a public health legacy of the London Olympic and Paralympic Games 2012, receiving routine data from emergency departments (EDs) across England, captured through the Emergency Care Dataset (ECDS). ${ }^{2-4}$ This anonymised subset of ECDS data is received on a daily basis, enabling a near real-time syndromic surveillance service, which feeds into PHE public health monitoring activities (including the COVID-19 response) and with weekly EDSSS surveillance bulletins made publicly available. ${ }^{5} 6$ The EDSSS is an unvalidated 'snapshot' of raw ED data (updates or completion of missing data are not included), which can be used for timely analysis and identification of trends for public health purposes.

In this short report we use routine EDSSS data to describe the changes in ED attendances in England from 12 March 2020, and the subsequent challenges that this has brought to undertaking ED syndromic surveillance.

\section{METHODS}

\section{Attendance data}

Daily ED attendance data were accessed from EDSSS from 1 January 2019 to 26 April 2020 (routine, anonymised, public health surveillance data, no ethical approval required). Selection criteria for inclusion were: type $1 \mathrm{ED}$ attendances; EDs reporting attendances for every day during the study period. EDSSS includes only EDs located in England.

ED attendances categorised by syndromic indicator were identified based on the primary diagnosis listed for each attendance (if any). In this report, syndromic indicators routinely identified in EDSSS were acute respiratory infections, gastroenteritis and myocardial ischaemia.

\section{Descriptive analysis}

Daily attendances were visualised by calendar years (2019 full year; 2020 to 26 April 2020), by age group (0, 1-4 and 15-14, 15-44, 45-64 and 65+years) and separately by acuity of attendance (ECDS values from 1 (immediate) to 5 (low acuity)).

Separate comparable time periods, matched on day of the week, were identified for the 2019 'pre-COVID-19' period (Thursday 14 March 2019 to Sunday 28 April 2019) and the 2020 'COVID-19' period during the delay phase (Thursday 12 March 2020 to Sunday 26 April 2020). The mean number of all-cause all-age attendances were plotted by hour of day and day of the week for both the pre-COVID-19 and COVID-19 periods.

The average daily attendances were calculated with the percentage difference between pre-COVID-19 and COVID-19 in total by sex, age group, acuity, day of the week and by selected syndromic surveillance indicators.

\section{RESULTS}

A total of 109 type 1 EDs met the inclusion criteria, reporting a total of 13861 889 attendances to EDSSS from 1 January 2019 to 26 April 2020.

Daily attendances by age group to 11 March 2020 showed similar trendsthat is, peak attendances on Monday and a notable reduction in child attendances during school holidays. From 12 March 2020 the numbers of daily attendances rapidly decreased across all age groups (figure 1).

The largest percentage change reduction in attendances was in school age children (table 1). There was no clear difference 

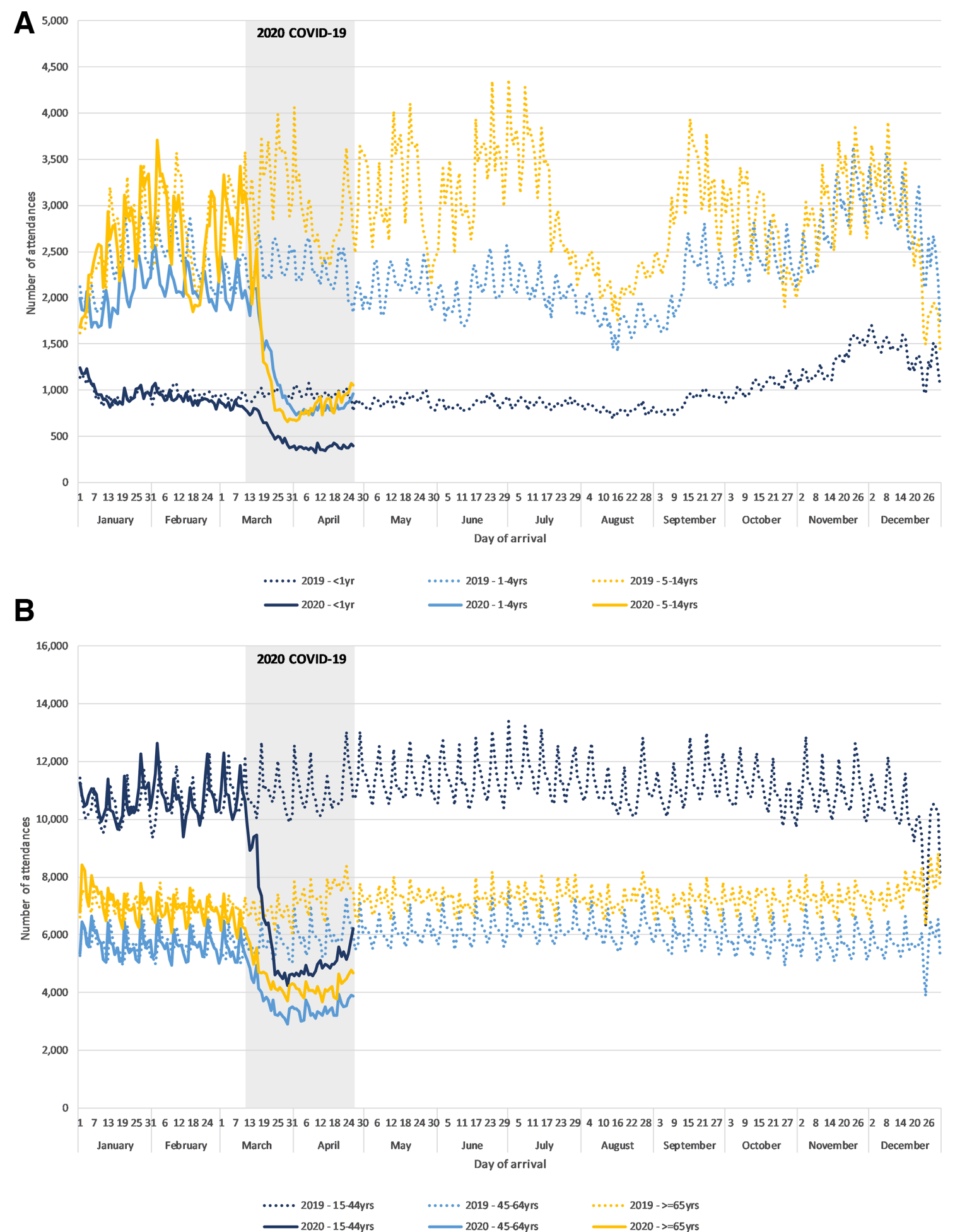

Figure 1 Daily Emergency Department Syndromic Surveillance System attendances in 2019 and 2020 by age group for (A) children and (B) adults ( $n=109$ EDs). The 2020 COVID-19 period (12 March 2020 to 26 April 2020) is marked in grey.

by gender (table 1). Age and gender were reported for $>99.5 \%$ of all attendances in both years.

The level of acuity was identifiable in $83.6 \%$ of all attendances $(82.9 \%$ pre-COVID-19; $83.5 \%$ COVID-19). Those with an acuity of ' 1 : immediate' accounted for the smallest numbers of
ED attendances and saw the smallest reduction in levels during COVID-19 (31\%), and those with an acuity of ' 4 : Standard' saw the largest reduction (54\%; table 1 and figure 2 ).

Attendance levels were reduced throughout the 24-hour period (figure 3). The largest decrease was seen on Monday to Wednesday, previously the busiest days of the week (table 1).

Syndromic indicators showed that the greatest reductions were in nonrespiratory indicators. While there was only a $4 \%$ reduction in acute respiratory infections, non-respiratory indicators fell by $44-67 \%$ during COVID-19 (table 1 ). 
Table 1 Differences in ED attendances between 2019 pre-COVID-19 and 2020 COVID-19 (based on the periods 14 March 2019 to 28 April 2019 and 12 March 2020 to 26 April 2020, respectively, matched on day of the week)

\begin{tabular}{|c|c|c|c|}
\hline & $\begin{array}{l}2019 \\
\text { pre-COVID-19 }\end{array}$ & $\begin{array}{l}2020 \\
\text { COVID-19 }\end{array}$ & $\begin{array}{l}\text { Percentage change } \\
(95 \% \mathrm{Cl})\end{array}$ \\
\hline Total & 30412 & 16217 & $-46.7 \%(-50.4 \%$ to $-42.9 \%)$ \\
\hline \multicolumn{4}{|l|}{ Age } \\
\hline$<1$ year & 954 & 471 & $-50.6 \%(-55.2 \%$ to $-46.1 \%)$ \\
\hline $1-4$ years & 2318 & 1068 & $-53.9 \%(-59.4 \%$ to $-48.5 \%)$ \\
\hline $5-14$ years & 3026 & 1075 & $-64.5 \%(-70.8 \%$ to $-58.2 \%)$ \\
\hline $15-44$ years & 10982 & 5636 & $-48.7 \%(-53.0 \%$ to $-44.4 \%)$ \\
\hline $45-64$ years & 5842 & 3596 & $-38.5 \%(-42.0 \%$ to $-34.9 \%)$ \\
\hline$\geq 65$ years & 7143 & 4360 & $-39.0 \%(-42.1 \%$ to $-35.8 \%)$ \\
\hline \multicolumn{4}{|l|}{ Gender } \\
\hline Female & 15438 & 8171 & $-47.1 \%(-50.6 \%$ to $-43.5 \%)$ \\
\hline Male & 14959 & 8020 & $-46.4 \%(-50.4 \%$ to $-42.4 \%)$ \\
\hline \multicolumn{4}{|l|}{ Day of the week } \\
\hline Monday & 33594 & 16778 & $-50.1 \%(-59.3 \%$ to $-40.9 \%)$ \\
\hline Tuesday & 31394 & 15627 & $-50.2 \%(-59.2 \%$ to $-41.2 \%)$ \\
\hline Wednesday & 30498 & 15385 & $-49.6 \%(-55.4 \%$ to $-43.7 \%)$ \\
\hline Thursday & 30241 & 16752 & $-44.6 \%(-55.3 \%$ to $-33.9 \%)$ \\
\hline Friday & 29682 & 16456 & $-44.6 \%(-53.5 \%$ to $-35.6 \%)$ \\
\hline Saturday & 28675 & 16358 & $-43.0 \%(-52.8 \%$ to $-33.1 \%)$ \\
\hline Sunday & 29410 & 16042 & $-45.5 \%(-54.2 \%$ to $-36.7 \%)$ \\
\hline \multicolumn{4}{|l|}{ Acuity } \\
\hline 1: Immediate & 370 & 256 & $-30.7 \%(-33.9 \%$ to $-27.6 \%)$ \\
\hline 2: Very urgent & 2336 & 1504 & $-35.6 \%(-38.2 \%$ to $-33.0 \%)$ \\
\hline 3: Urgent & 9416 & 5642 & $-40.1 \%(-43.5 \%$ to $-36.7 \%)$ \\
\hline 4: Standard & 11818 & 5455 & $-53.8 \%(-58.0 \%$ to $-49.7 \%)$ \\
\hline 5: Low acuity & 1284 & 684 & $-46.7 \%(-54.3 \%$ to $-39.0 \%)$ \\
\hline \multicolumn{4}{|l|}{ Selected syndromic indicators } \\
\hline Acute respiratory infections & 1757 & 1679 & $-4.4 \%(-9.5 \%$ to $0.6 \%)$ \\
\hline Gastroenteritis & 356 & 118 & $-66.9 \%(-71.4 \%$ to $-62.4 \%)$ \\
\hline Myocardial ischaemia & 357 & 199 & $-44.2 \%(-48.8 \%$ to $-39.7 \%)$ \\
\hline
\end{tabular}

\section{DISCUSSION}

During the 2020 COVID-19 period there were fewer daily ED attendances than in the 2019 pre-COVID-19 period. The largest percentage reductions were observed on Monday to Wednesday (previously the busiest days of the week) and in the youngest age groups (particularly school age children). The reduction was observed across all acuity categories, although it was less marked in the most severe attendance presentations. These findings support and quantify a recent Royal College of Emergency Medicine position statement in the UK and also corroborate similar recent findings from the USA. ${ }^{78}$

EDSSS reports on high level groupings of disease/condition indicators which provide additional depth of understanding of ED activity, particularly with respect to infectious diseases. While other official sources of ED activity data in the UK (eg, the NHS England weekly and monthly admission statistics ${ }^{9}$ ) provide information about overall attendance activity, they include other service metrics such as patient wait times to inform performance management. Routine reporting of EDSSS data supplements these other sources and illustrates a differential impact of the changes in healthcare seeking behaviour (in real-time)-for example, attendances for acute respiratory infections decreased very little but non-respiratory indicators reported here decreased by $44-67 \%$. Monitoring these changes in healthcare utilisation through surveillance is key to understanding the impact of COVID-19 in the population. These syndromic surveillance data demonstrate possible indirect impacts of social distancing/shielding, both positive (eg, reduced need for gastroenteritis attendances) and negative (eg, emergency cardiac care potentially avoided). Recent public health messaging has urged patients to continue to seek medical care as required. ${ }^{10}$

The routine nature of the EDSSS enabled the rapid comparison of pre- and current COVID-19 periods to describe the impact using a large subset of English type 1 ED attendances. However, this analysis is limited by the intentional exclusion of all non-type $1 \mathrm{ED}$ attendances and some type $1 \mathrm{ED}$ attendances due to inconsistency in the frequency of data submission. The intention is for NHS acute data to be submitted to NHS Digital, using ECDS, on a daily basis. ${ }^{4}$

One of the biggest challenges for EDSSS has been changes in the total attendances which led to difficulty interpreting syndromic indicators as a percentage of attendances, resulting in false signals. EDSSS reporting was subsequently rapidly adapted, with attendance counts (as used here) presented in all standard EDSSS reporting from 19 March 2020. ${ }^{5}$ Supplementary EDSSS developments will include severity indicators to provide enhanced intelligence in future.

The EDSSS now reports on COVID-19like attendances (including new COVID-19 SNOMED codes ${ }^{11}$ ). This information now feeds into the PHE COVID-19 response, demonstrating that the information is actionable, as well as in regular weekly EDSSS surveillance bulletins. ${ }^{5} 6$ Furthermore, EDSSS outputs are also used by the UK Government to support and guide management of the pandemic. EDSSS will continue to be used during the COVID-19 pandemic, delivering real-time monitoring of indicators of both direct (respiratory) and indirect (non-respiratory) healthcare demand. It will also provide valuable surveillance information during any future waves and inform on healthcare pressures during winter 2020/21 when SARS-CoV-2 and other seasonal respiratory pathogens will impact on emergency care services. ${ }^{12}$

\section{CONCLUSION}

ED attendances in England have been affected by changes in healthcare seeking behaviour during the COVID-19 pandemic. EDSSS has enabled realtime daily monitoring of these changes, providing publicly available information to facilitate action. The EDSSS provides valuable surveillance of ED attendances in England. The flexibility of EDSSS allowed rapid development of new indicators (including COVID-19-like) and changes to reporting methods as required.

Acknowledgements The authors acknowledge the contribution and support from the ED clinicians and Trust staff in the EDSSS; the ongoing support of the Royal College of Emergency Medicine; and the technical support provided by NHS Digital.

Contributors HEH: Study design, data preparation, data analysis, drafting the manuscript, critical revision and final approval of the manuscript. TCH: Study design, critical revision and final approval of the manuscript. RM: Study design, data analysis, critical revision and final approval of the manuscript. KC: Study design, critical revision and final approval of the manuscript. IO: Study design, critical revision and final 


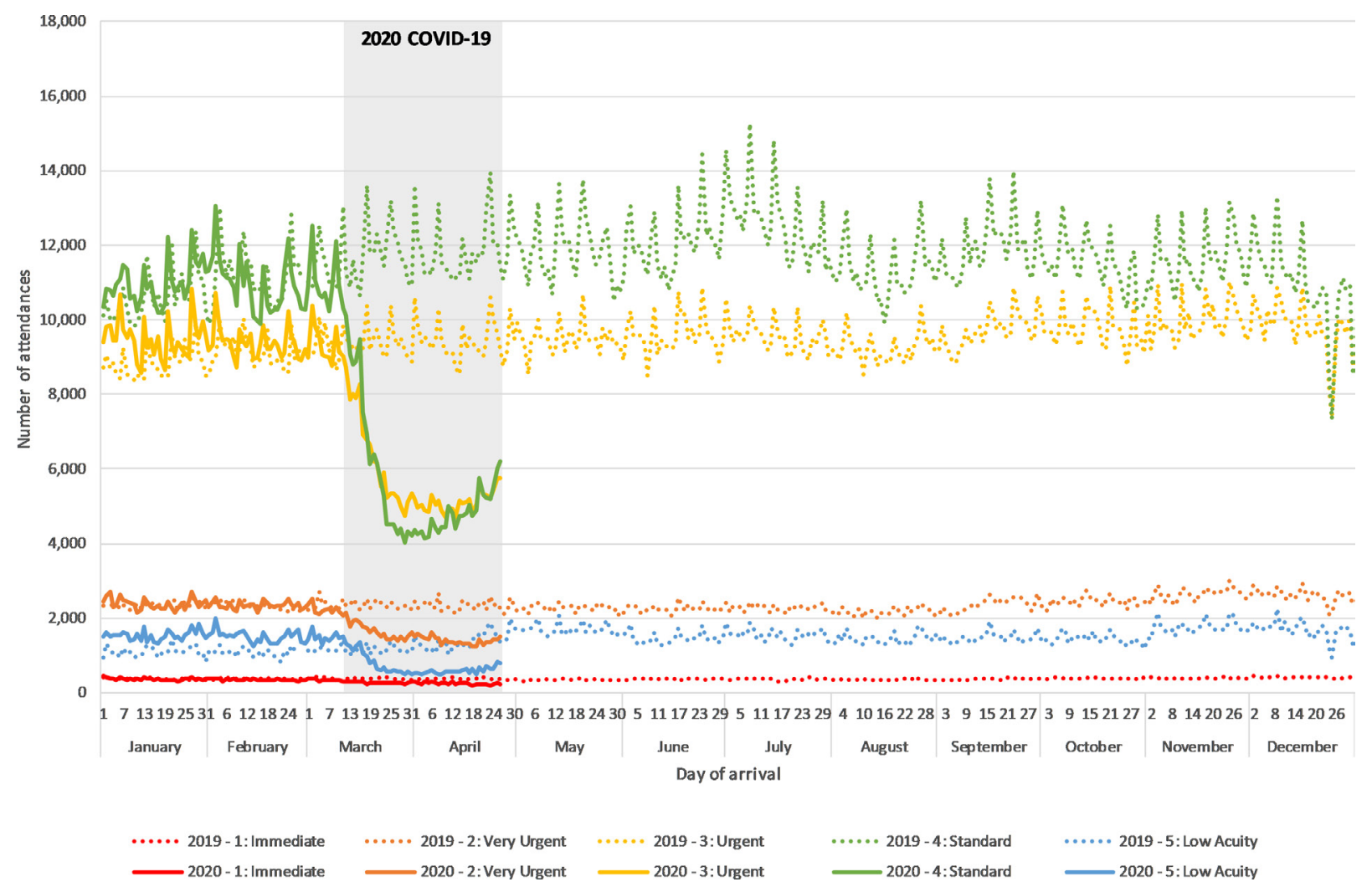

Figure 2 Daily Emergency Department Syndromic Surveillance System attendances in 2019 and 2020 by acuity, where known (n=109 EDs). The 2020 COVID-19 period (12 March 2020 to 26 April 2020) is marked in grey.

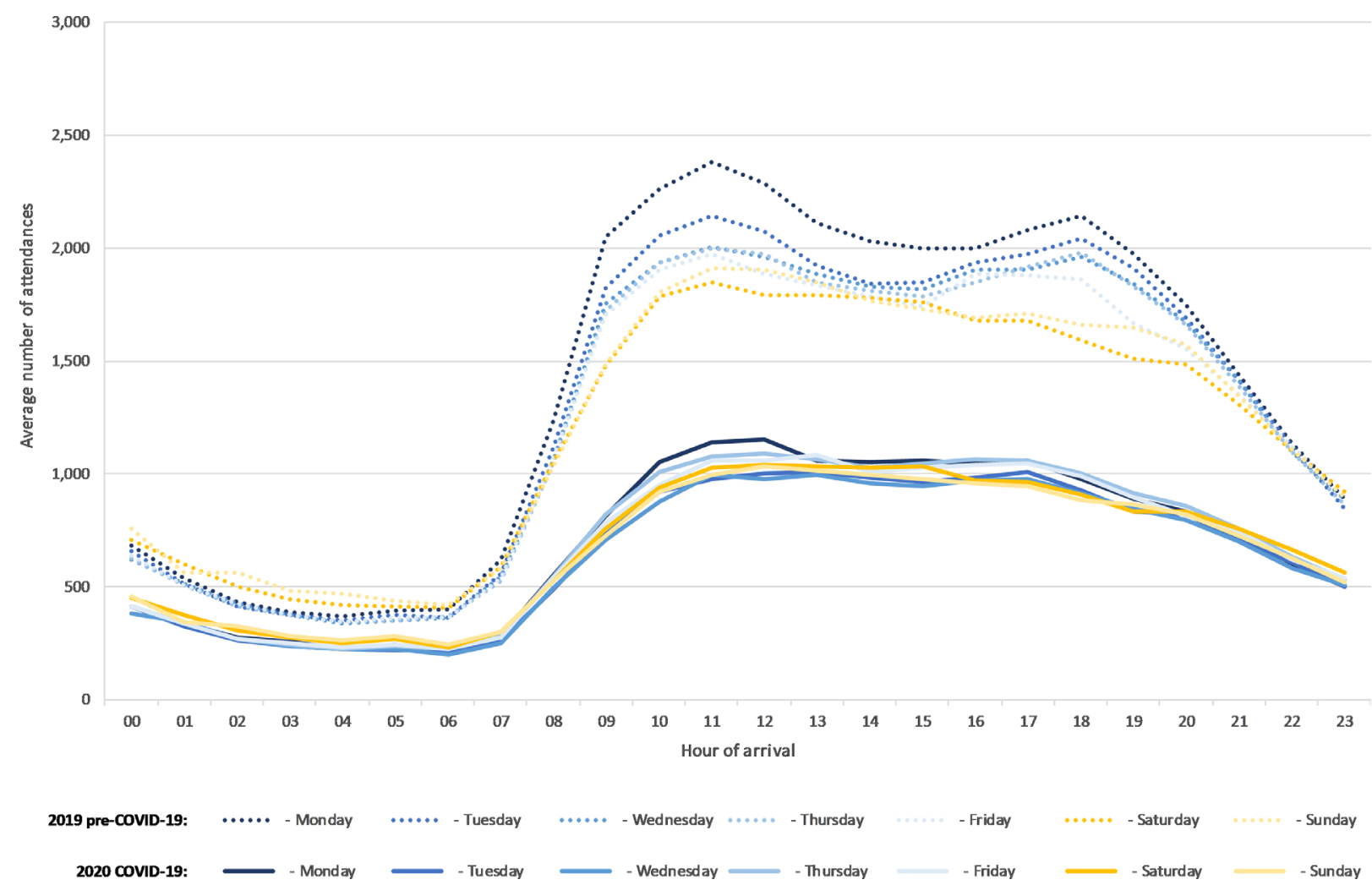

Figure 3 Emergency Department Syndromic Surveillance System attendances by hour of day and day of week during the 2019 pre-COVID-19 and 2020 COVID-19 periods (based on the periods 14 March 2019 to 28 April 2019 and 12 March 2020 to 26 April 2020, respectively, matched on day of the week). 
approval of the manuscript. GS: Study design, critical revision and final approval of the manuscript. AJE: Study design, drafting the manuscript, critical revision and final approval of the manuscript.

Funding HEH and AJE receive support from the National Institute for Health Research Health Protection Research Unit (NIHR HPRU) in Gastrointestinal Infections. GS, RM and AJE receive support from the NIHR HPRU in Emergency Preparedness and Response. IO receives support from the NIHR HPRU in Behavioural Science and Evaluation.

Disclaimer The views expressed are those of the author(s) and not necessarily those of the NIHR, Public Health England or the Department of Health and Social Care.

Competing interests $\mathrm{TCH}$ is a director of $\mathrm{L} 2 \mathrm{~S} 2 \mathrm{Ltd}$. Patient and public involvement Patients and/or the public were not involved in the design, or conduct, or reporting, or dissemination plans of this research.

Patient consent for publication Not required.

Provenance and peer review Not commissioned; externally peer reviewed.

Data availability statement No data are available Restrictions apply to the availability of the data that support the findings of this study. Surveillance outputs and limited data are routinely available at https://www. gov.uk/government/collections/syndromic-surveillancesystems-and-analyses and can be used acknowledging the source.$$
\text { (2) }
$$$$
\text { OPEN ACCESS }
$$

Open access This is an open access article distributed in accordance with the Creative Commons Attribution 4.0 Unported (CC BY 4.0) license, which permits others to copy, redistribute, remix, transform and build upon this work for any purpose, provided the original work is properly cited, a link to the licence is given, and indication of whether changes were made. See: https:// creativecommons.org/licenses/by/4.0/.

(c) Author(s) (or their employer(s)) 2020. Re-use permitted under CC BY. Published by BMJ.

Handling editor Ed Benjamin Graham Barnard

$$
\text { Check for updates }
$$

To cite Hughes HE, Hughes TC, Morbey R, et al. Emerg Med J 2020;37:600-604.

Received 11 May 2020

Revised 30 July 2020

Accepted 3 August 2020

Published Online First 18 September 2020

Emerg Med J 2020;37:600-604

doi:10.1136/emermed-2020-209980

\section{ORCID iDs}

Helen E Hughes http://orcid.org/0000-0002-3664-2983

Thomas C Hughes http://orcid.org/0000-0001-5490-

1267

Roger Morbey http://orcid.org/0000-0001-8543-477X

Kirsty Challen http://orcid.org/0000-0003-4032-5531

Isabel Oliver http://orcid.org/0000-0002-6106-1734

Gillian E Smith http://orcid.org/0000-0002-4257-0568

Alex J Elliot http://orcid.org/0000-0002-6414-3065

\section{REFERENCES}

1 Department of Health and Social Care. COVID-19: government announces moving out of contain phase and into delay, 2020. Available: https://www.gov.uk/ government/news/covid-19-government-announcesmoving-out-of-contain-phase-and-into-delay [Accessed 6 May 2020].

2 NHS England. Emergency care data set (ECDS), 2016. Available: https://www.england.nhs.uk/ourwork/tsd/ ec-data-set/ [Accessed 6 May 2020].

3 Hughes HE, Hughes TC, Haile A, et al. Syndromic surveillance revolution? Public health benefits of modernizing the emergency care patient health record in England. Public Health Rep 2017;132:12S-15.
4 NHS Digital. Emergency care data set (ECDS), 2020. Available: https://digital.nhs.uk/data-and-information/ data-collections-and-data-sets/data-sets/emergencycare-data-set-ecds [Accessed 6 May 2020].

5 Public Health England. Syndromic surveillance: systems and analyses: emergency department syndromic surveillance system, 2020. Available: https://www.gov.uk/government/collections/ syndromic-surveillance-systems-and-analyses\# emergency-department-syndromic-surveillancesystem [Accessed 4 May 2020].

6 Public Health England. Research and analysis: national COVID-19 surveillance reports, 2020. Available: https://www.gov.uk/government/ publications/national-covid-19-surveillancereports [Accessed 26 Jun 2020].

7 Royal College of Emergency Medicine. RCEM position statement. COVID-19: resetting emergency department care, 2020. Available: https://www.rcem.ac.uk/docs/ Policy/RCEM_Position_statement_Resetting_Emergency_ Care_20200506.pdf [Accessed 26 Jun 2020].

8 Hartnett KP, Kite-Powell A, DeVies J, et al. Impact of the COVID-19 pandemic on emergency department visits - United States, January 1 2019-May 30, 2020. MMWR Morb Mortal Wkly Rep 2020;69:699-704.

9 NHS Digital. Monthly Trust Situation Reports (MSitAE) data collection. Available: https://digital.nhs.uk/dataand-information/data-collections-and-data-sets/datacollections/monthly-trust-situation-reports-msitaedata-collection [Accessed 26 Jun 2020].

10 NHS. Help us help you: NHS urges public to get care when they need it, 2020. Available: https://www. england.nhs.uk/2020/04/help-us-help-you-nhs-urgespublic-to-get-care-when-they-need-it/ [Accessed 4 May 2020]

11 NHS Digital. ECDS latest update: recording ECDS instances of COVID-19, 2020. Available: https://digital. nhs.uk/data-and-information/data-collections-and-datasets/data-sets/emergency-care-data-set-ecds/ecds-latestupdate [Accessed 4 May 2020].

12 Hughes HE, Morbey R, Hughes TC, et al. Emergency department syndromic surveillance providing early warning of seasonal respiratory activity in England. Epidemiol Infect 2016;144:1052-64. 